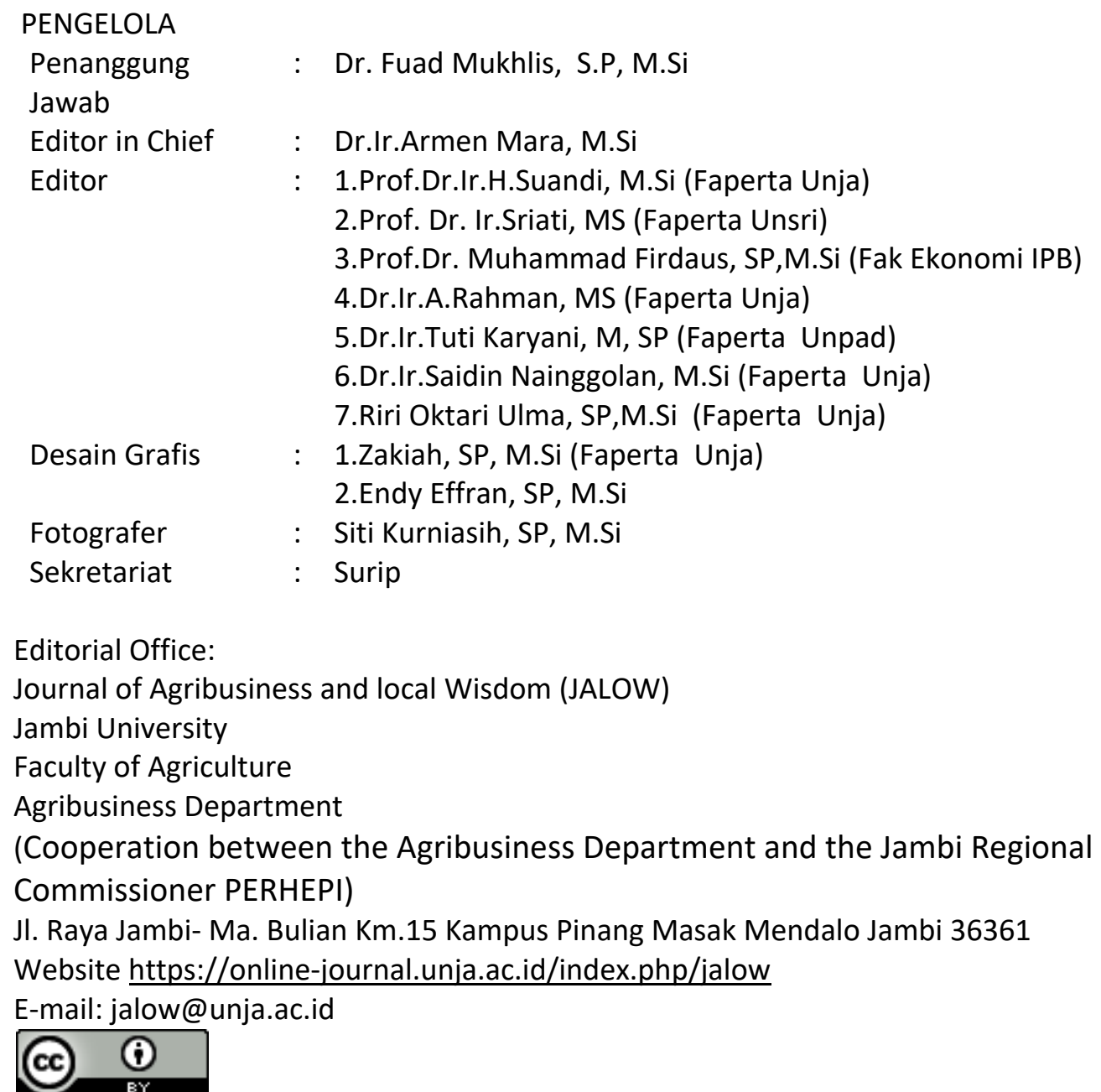

This work is licensed under a Creative Commons Attribution 4.0 International License. 


\section{Assalamualaikum wbwb}

\section{PENGANTAR}

Kondisi agribisnis tahun 2020 ini agak berbeda dengan tahun sebelumnya. Kebijakan penanggulangan Covid19 seperti "dirumah Aja, lockdown lokasi, Isolasi Mandiri, PSBB (Pembatasan Sosial Berskala Besar), dan Herd Immunity" telah merubah pola aktivitas masyarakat, khususnya di Kota-kota. Sebelumnya, berkejar2an dengan waktu untuk meningkatkan pendapatan dengan jalan menambah produktivitas dan menekan biaya telah dikagetkan oleh adanya ancaman pandemi Covid19 yang ada dimana-mana, semangat berkejar-kejaran tersebut kendur seketika.

Kegiatan perdagangan di Kota-kota besar maupun kota kecil telah mengalami kelesuan untuk semua lapisan, mulai dari pedagang kecil mikro, pedagang asongan atau gerobak, pedagang toko, mini market sampai perdagangan berskala besar, super market, dan mallmall. Hal ini menyebabkan terjadinya pengangguran, berkurangnya pendapatan masyarakat dan menurun drastisnya penerimaan pemerintah dari pajak. Selama masa isolasi, para konsumen melakukan belanja dengan sangat hati-hati. Pihak produsen merasakan berkurangnya permintaan. Oleh karena itu, walaupun kebijakan Covid19 tidak menghambat aktivitas produksi pertanian di lahan secara langsung namun karena permintaan berkurang maka berkurang pula pendapatan petani yang mengusahakan kebun atau sawah.

Kebiasaan konsumen yang selama ini lebih banyak makan di luar rumah berubah menjadi lebih banyak makan di rumah sendiri, masak sendiri atau pesan antar. Berbelanja yang semula mencari tempat2 yang banyak di kerumuni orang berubah ke tempat yang tidak ada kerumunannya, artinya rasa enak dan harga murah tidak lagi menjadi patokan utama bagi konsumen. Mereka lebih mengutamakan sehat dan terjamin dalam proses pembuatannya. Kesadaran adanya ancaman bahaya serangan Covid19 terhadap nyawa setiap orang telah menyebabkan berubah nya psikologi dan sosial masyarakat. Sebelumnya berpikir materialis dan untung rugi dari setiap kerja, sekarang mulai nampak adanya kepedulian terhadap perintah agama melaksanakan sholat dan bersedekah. Mulai terlihat adanya aktivitas sosial di tengah-tengah kota, ada kegiatan membagikan nasi bungkus kepada kaum duafah dan lapisan bawah, kegiatan membagikan sembako, membagikan ampelop berisi uang kertas, sampai pada aktivitas memberikan tip berupa uang dalam setiap kali berbelanja di pedagang-pedagang kecil.

Harapan untuk semua aktivitas-aktivitas positif tersebut berlangsung tidak sementara tapi menjadi karakter bagi setiap orang. Kalau aktivitas sosial ini terus dipertahankan oleh pelaku yang telah memulai nya tentu akan diikuti juga oleh yang lainnya. Diharapkan juga setiap pelaku agribisnis berskala kecil, baik yang disektor produksi pertanian maupun sektor industri pengolahan dan perdagangan dapat mengantisipasi perubahan prilaku konsumen tersebut dengan perubahan pola produksi yang sesuai sehingga peluang bisnis yang terlepas dari pola sebelumnya dapat ditangkap.

Demikian semoga JALOW untuk penerbitan ini bermanfaat untuk kita semua aamiin ya robbal aalamiin.

Waalaikumsalam wbwb

Editor in Chief

Dr.Ir.Armen Mara,M.Si 
DAFTAR ISI

\begin{tabular}{|c|c|c|}
\hline 1 & $\begin{array}{l}\text { ANALISIS RESPON PENAWARAN KOMODITI KEDELAI } \\
\text { DI KABUPATEN TANJAB TIMUR } \\
\text { Oleh Edison }\end{array}$ & $1-10$ \\
\hline 2 & 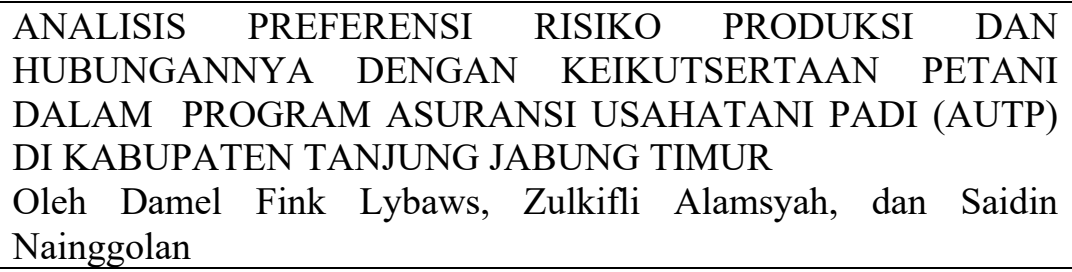 & $11-27$ \\
\hline 3 & $\begin{array}{l}\text { ANALISIS USAHA IKAN HIAS AIR TAWAR DI KOTA JAMBI (ANALYSIS } \\
\text { OF FRESH WATER ORNAMENTAL FISH IN JAMBI CITY) } \\
\text { Dody Hadisaputra, Ernawati, Suandi }\end{array}$ & $28-40$ \\
\hline 4 & $\begin{array}{l}\text { ANALISIS FAKTOR-FAKTOR YANG MEMPENGARUHI PRODUKSI } \\
\text { BOKAR (BAHAN OLAH KARET) DI KABUPATEN BATANGHARI } \\
\text { Oleh Elisabeth Lumban Gaol, Armen Mara, dan Riri Oktari UIma }\end{array}$ & $41-52$ \\
\hline 5 & $\begin{array}{l}\text { ANALISIS PENGAMBILAN KEPUTUSAN UNTUK PEMBELIAN } \\
\text { MAKANAN KEMASAN BERLOGO HALAL MUI (STUDI KASUS IBU } \\
\text { RUMAH TANGGA DI PERUMAHAN AUR DURI DAN PERUMNAS KOTA } \\
\text { BARU, KOTA JAMBI) } \\
\text { Oleh Putri Hana Jusia, Saad Murdy, Lavlinesia }\end{array}$ & $53-66$ \\
\hline 6 & \begin{tabular}{lrrrr} 
STRATEGI & ADAPTASI & PETANI & DALAM & \multicolumn{2}{l}{ MENGHADAPI } \\
RENDAHNYA & HARGA & JUAL & KELAPA & SAWIT DI \\
KECAMATAN & SUNGAI & BAHAR & KABUPATEN & MUARO \\
JAMBI & & & \\
Oleh Fiona Andini & ), Fuad Muchlis $^{2}$ ), Aulia Farida 2) \\
\end{tabular} & $67-73$ \\
\hline 7 & \begin{tabular}{lcllr}
\multicolumn{2}{l}{ KOLABORASI } & DALAM & PENGELOLAAN & \multicolumn{2}{c}{ PERKEBUNAN } \\
KELAPA SAWIT & RAKYAT & (STUDI KASUS: KUD & LUBUK \\
KARYA DAN & KUD & KAMPUNG & SURAU & KAB. \\
DHARMASRAYA & & & & \\
Oleh Yulistriani & & & & \\
\end{tabular} & $74-81$ \\
\hline 8 & $\begin{array}{l}\text { KEPUTUSAN PETANI SAWIT DALAM MENGKONVERSI } \\
\text { LAHAN KELAPA SAWIT MENJADI LAHAN PADI SAWAH DI } \\
\text { KECAMATAN BATANG ASAM KABUPATEN } \\
\text { TANJUNG JABUNG BARAT } \\
\text { Oleh Krielson Ompusunggu1), Arsyad Lubis2, Siti Kurniasih2 }\end{array}$ & $82-88$ \\
\hline 9 & $\begin{array}{l}\text { KAITAN BIAYA DAN TEKNIK PEREMAJAAN } \\
\text { KELAPA SAWIT RAKYAT } \\
\text { Oleh Nur Imdah Minsyah }\end{array}$ & $89-99$ \\
\hline 10 & $\begin{array}{l}\text { STRATEGI RANTAI PASOK KELAPA SAWIT DI PROVINSI } \\
\text { SUMATERA BARAT } \\
\text { Oleh Rahma Dzulqa1*), Rika Ampuh Hadiguna2) }\end{array}$ & 100 \\
\hline
\end{tabular}




\title{
STRATEGI ADAPTASI PETANI DALAM MENGHADAPI RENDAHNYA HARGA JUAL KELAPA SAWIT DI KECAMATAN SUNGAI BAHAR KABUPATEN MUARO JAMBI
}

\author{
Fiona Andini'), Fuad Muchlis ${ }^{2}$, Aulia Farida ${ }^{2)}$ \\ ${ }^{1)}$ Mahasiswa Prodi Agribisnis Fakultas Pertanian Universitas Jambi \\ ${ }^{2)}$ Dosen Prodi Agribisnis Fakultas Pertanian Universitas Jambi \\ korespondensi: Tel. +6282312881544 \\ Email : fionaandini08@gmail.com
}

\begin{abstract}
This study aims to determine the adaptation strategies of farmers in the face of low prices for oil palm in Sungai Bahar District. The data used are primary data obtained from direct interviews with respondents and secondary data obtained from literature and related institutions. The method used in this research is mixed methods. Data analysis is done by collecting data and analyzing quantitative data in the first stage, then collecting data and analyzing qualitative data in the second stage, then analyzing the overall data to then draw conclusions from the analysis of the data. The analysis methods are: (1) Data reduction; (2) Presentation of data and; (3) Drawing conclusions.

The results showed that the adaptation strategies used were: (1) active strategy, becoming an oil palm farm laborer, opening a side business; (2) a passive strategy, utilizing home yards to grow horticultural crops, raising / raising chickens; (3) network strategy, borrowing money from relatives / neighbors, borrowing money from tauke and borrowing / borrowing daily necessities at the shop / shop.
\end{abstract}

Keywords: price fluctuations, low selling prices, adaptation strategies.

\section{PENDAHULUAN}

Sektor pertanian memiliki peranan penting dalam perekonomian Indonesia salah satunya adalah sub sektor perkebunan, dimana komoditas perkebunan merupakan andalan bagi pendapatan nasional dan devisa negara Indonesia. Kontribusi sub sektor perkebunan terhadap perekonomian nasional semakin meningkat dan diharapkan dapat memperkokoh pembangunan perkebunan secara menyeluruh. Salah satu sub sektor pekebunan yang banyak diusahakan di indonesia adalah kelapa sawit. Sebagaimana daerah lainnya di Indonesia, sebagian besar penduduk Provinsi Jambi yang tinggal di daerah pedesaan bermata pencarian utama di sub sektor perkebunan. Salah satu Kabupaten di Provinsi Jambi yang mengusahakan kelapa sawit adalah Kabupaten Muaro Jambi yang mempunyai luas lahan terbesar dibandingkan dengan 8 Kabupaten lainnya di Provinsi Jambi yaitu sebesar $97.749 / \mathrm{Ha}$. Salah satu kecamatan yang mengusahakan kelapa sawit di Kabupaten Muaro Jambi adalah Kecamatan Sungai Bahar. Kecamatan Sungai Bahar merupakan wilayah yang memiliki luas areal perkebunan kelapa sawit terbesar pertama yaitu sebesar 27.286 ha pada tahun 2017, dibandingkan kecamatan lainnya di Kabupaten Muaro Jambi (Dinas Perkebunan Provinsi Jambi Tahun 2017).

Perkebunan kelapa sawit di Kecamatan Sungai Bahar menjadi komoditi utama sebagai mata pencarian masyarakatnya. Tinggi rendahnya pendapatan petani kelapa sawit tergantung pada harga yang diterima petani dan produktivitas kelapa sawit yang 
dihasilkan. Kebun kelapa sawit di Sungai Bahar rata- rata berusia 25-35 tahun dan sudah tidak produktif lagi tetapi masih banyak petani yang enggan melakukan peremajaan dan tetap mempertahankannya. Harga TBS yang berfluktuasi dan bahkan terkadang cenderung turun, ditambah dengan kelapa sawit yang sudah tidak produktif lagi mengakibatkan pendapatan rumah tangga petani kelapa sawit di Kecamatan Sungai Bahar menjadi tidak stabil. Terjadinya penurunan harga TBS yang cukup drastis pada tahun 2015 yaitu sebesar 967/kg (Dinas Perkebunan Provinsi Jambi Tahun 2017), mengakibatkan kondisi ekonomi petani kelapa sawit melemah sedangkan biaya dan upah untuk produksi kelapa sawit tidak turun, sementara mereka harus memenuhi kebutuhan keluarga maupun biaya lainnya.

Strategi bertahan hidup adalah rangkaian tindakan yang dipilih secara sadar oleh individu. Melalui strategi ini, seseorang bisa berusaha untuk menambah penghasilan lewat pemanfaatan sumber-sumber lain ataupun mengurangi pengeluaran lewat pemanfaatan sumber lain. Harga TBS yang berfluaktif dan terkadang cenderung rendah membuat petani melakukan berbagai strategi untuk memastikan pendapatan petani tetap cukup dalam memenuhi kebutuhan hidupnya (Lestari, 2015).

\section{METODE PENELITIAN}

Penelitian ini dilaksanakan di dua desa Kecamatan Sungai Bahar, yaitu Desa Marga Mulya dan Desa Bukit Makmur. Pemilihan lokasi dilakukan secara sengaja (purposive). Objek dalam penelitian ini adalah petani kelapa sawit yang hanya menggantungkan hidupnya dari hasil kebun kelapa sawitnya. Penelitian ini dilakukan untuk mengetahui strategi adaptasi yang digunakan petani dalam menghadapi rendahnya harga jual kelapa sawit. Pelaksanaan penelitian ini dilaksanakan pada Tanggal 19 Agustus 2019 sampai 19 September 2019.

Jenis data yang dikumpulkan dalam penelitian ini meliputi data primer dan data skunder. Data primer dalam penelitian ini diperoleh dengan cara observasi dan wawancara langsung kepada responden, sedangkan data sekunder merupakan data yang diperoleh dari berbagai literatur dan instansi terkait. Metode pengumpulan data yang digunakan pada penelitian ini yaitu dengan cara survei, observasi dan wawancara menggunakan kuesioner.

Metode penarikan sampel ditentukan secara sengaja (purposive), Jumlah petani yang dijadikan sampel pada penelitian ini sebanyak 43 orang. Analisis data dilakukan dengan cara mengumpulkan data dan menganalisis data kuantitatif pada tahap pertama, kemudian melakukan pengumpulan data dan menganlisis data kualitatif pada tahap kedua, selanjutnya menganilis data secara keseluruhan untuk kemudian di ambil kesimpulan dari analisis data tersebut. Analisis data kuantitatif pada penelitian ini digunakan untuk menghitung skor dan persentase yang terdapat pada lembar kuisioner, sedangkan analisis data kualitatif digunakan untuk melengkapi gambaran yang diperoleh dari analisis data kuantitatif, yang menggunakan teknik analisis data kualitatif dari Miles dan Huberman, yaitu : 
1. Reduksi Data

2. Penyajian Data

3. Kesimpulan dan Verifikasi

\section{HASIL DAN PEMBAHASAN}

\section{Gambaran Umum Lokasi Penelitian}

Kecamatan Sungai Bahar merupakan salah satu dari 11 kecamatan yang ada dalam wilayah Kabupaten Muaro Jambi. Kecamatan Sungai Bahar dengan topografi datar, memiliki luas wilayah $+20770,80 \mathrm{Km} 2$. Kecamatan Sungai Bahar terletak diantara $103030^{\circ} 0^{\prime \prime}$ BT - $10400^{\circ} 0^{\prime \prime}$ dan $1030^{\circ} 0^{\prime \prime}-200^{\prime} 0^{\prime \prime}$ LS dengan batas - batas wilayah yaitu :

a. Sebelah utara, berbatasan dengan Kecamatan Bahar Utara dan Kecamatan Mestong

b. Sebelah timur, berbatasan dengan Propinsi Sumatra Selatan

c. Sebelah selatan, berbatasan dengan Kecamatan Bahar Selatan

d. Sebelah barat, berbatasan dengan Kabupaten Batang Hari Jumlah penduduk di Kecamatan Sungai Bahar pada tahun 2017 tercatat sebanyak 26.543 jiwa yang terdiri dari penduduk laki-laki 13.560 jiwa dan penduduk perempuan 12.983 jiwa. Mata pencaharian penduduk di Kecamatan Sungai Bahar bervarariasi yaitu sebagai petani, buruh tani, pedagang, PNS dan sebagainya.

Strategi Adaptasi Petani Dalam Mensiasati Rendahnya Harga Jual Kelapa Sawit Strategi Aktif

Menjadi Buruh tani

Tabel 1. Distribusi Frekuensi Responden Bekerja Sampingan Dengan Menjadi Buruh Tani Kelapa Sawit Di Kecamatan Sungai Bahar Kabupaten Muaro Jambi 2019.

\begin{tabular}{ccc}
\hline Buruh Tani Sawit & Frekuensi (Orang) & Persentase (\%) \\
\hline Ya & 24 & 55,8 \\
Tidak & 19 & 44,2 \\
\hline Jumlah & 43 & 100 \\
\hline
\end{tabular}

Sumber: Hasil Olahan Data Primer (2019)

Berdasarkan Tabel 1 menunjukkan bahwa dari 43 responden, terdapat 24 atau 55,8\% petani kelapa sawit memilih pekerjaan sampingan dengan menjadi buruh tani sawit dan 19 orang atau 44,2\% lainnya memilih tidak. Rendahnya tingkat pendidikan dan juga tidak adanya keahlian yang dimiliki, membuat sebagian para petani kelapa sawit terpaksa hanya melakukan pekerjaan sampingan sebagai buruh tani.

Membuka Usaha Sampingan

Tabel 2. Distribusi Frekuensi Responden Bekerja Sampingan Dengan usaha Kecil-Kecilan Di Kecamatan Sungai Bahar Kabupaten Muaro Jambi 2019.

\begin{tabular}{ccc}
\hline Usaha Kecil-kecilan & Frekuensi (Orang) & Persentase (\%) \\
\hline Ya & 5 & 11,6
\end{tabular}




\begin{tabular}{ccc} 
Tidak & 38 & 88,4 \\
\hline Jumlah & 43 & 100 \\
\hline
\end{tabular}

Sumber: Hasil Olahan Data Primer (2019)

Berdasarkan Tabel 2 menunjukkan bahwa dari 43 responden, hanya 5 atau 11,6\% petani kelapa sawit memilih pekerjaan sampingan dengan membuka usaha kecil-kecilan dan 38 orang atau $88,4 \%$ lainnya memilih tidak. Hasil penjualan kecil-kecilan ini hanya cukup untuk menambah uang dapur ataupun hanya untuk uang jajan anak-anak mereka.

\section{Strategi Pasif}

Pemanfaatan Pekarangan Rumah Untuk Menanam Tanaman Hortikultura

Tabel 3. Distribusi Frekuensi Responden Pemanfaatan Pekarangan Rumah Dengan Menanam Tanaman Hortikultura Di Kecamatan Sungai Bahar Kabupaten Muaro Jambi 2019.

\begin{tabular}{ccc}
\hline $\begin{array}{c}\text { Menanam Tanaman } \\
\text { Hortikultura }\end{array}$ & Frekuensi (Orang) & Persentase (\%) \\
\hline Ya & 35 & 81,4 \\
Tidak & 8 & 18,6 \\
\hline Jumlah & 43 & 100 \\
\hline
\end{tabular}

Sumber: Hasil Olahan Data Primer (2019)

Berdasarkan Tabel 3 menunjukkan bahwa dari 43 responden, terdapat 35 atau $81,4 \%$ petani kelapa sawit memanfaatkan pekarangan rumahnya untuk ditanami tanaman hortikultura dan hanya 8 orang atau $18,6 \%$ lainnya memilih tidak.

Pemanfaatan Pekarangan Rumah Untuk Ternak Ayam

Tabel 4. Distribusi Frekuensi Responden Pemanfaatan Pekarangan Rumah Dengan Memelihara/Ternak Ayam Di Kecamatan Sungai Bahar Kabupaten Muaro Jambi 2019.

\begin{tabular}{ccc}
\hline $\begin{array}{c}\text { Memelihara/Ternak } \\
\text { Ayam }\end{array}$ & Frekuensi (Orang) & Persentase (\%) \\
\hline Ya & 9 & 20,9 \\
Tidak & 34 & 79,1 \\
\hline Jumlah & 43 & 100 \\
\hline
\end{tabular}

Sumber: Hasil Olahan Data Primer (2019)

Berdasarkan Tabel 4 menunjukkan bahwa dari 43 responden, hanya terdapat 9 atau $20,9 \%$ petani kelapa sawit memanfaatkan pekarangan rumahnya untuk memelihara/ternak ayam dan 34 orang atau 79,1\% lainnya memilih tidak dengan berbagai macam alasan. Perawatan mudah dan sederhana menjadi alasan sebagian para petani mau memelihara/ternak ayam 


\section{Strategi Jaringan}

Meminjam Uang Kepada Kerabat Atau Tetangga

Tabel 5. Distribusi Frekuensi Responden Meminjam Uang Kepada Kerabat/Tetangga Di Kecamatan Sungai Bahar Kabupaten Muaro Jambi 2019.

\begin{tabular}{ccc}
\hline $\begin{array}{c}\text { Meminjam Uang Kepada } \\
\text { Kerabat/Tetangga }\end{array}$ & Frekuensi (Orang) & Persentase (\%) \\
\hline Ya & 31 & 72,1 \\
Tidak & 12 & 27,9 \\
\hline Jumlah & 43 & 100 \\
\hline
\end{tabular}

Sumber: Hasil Olahan Data Primer (2019)

Berdasarkan Tabel 5 menunjukkan bahwa dari 43 responden, terdapat 31 atau $72,1 \%$ petani kelapa sawit memanfaatkan kerabat/tetangga sekitar untuk meminjam uang saat mereka kekurangan/butuh uang untuk suatu dan hanya 12 orang atau $27,9 \%$ lainnya memilih tidak dengan berbagai alasan.

Meminjam Uang Kepada Tauke

Tabel 6. Distribusi Frekuensi Responden Meminjam Uang Kepada Tauke Di Kecamatan Sungai Bahar Kabupaten Muaro Jambi 2019.

\begin{tabular}{ccc}
\hline $\begin{array}{c}\text { Meminjam Uang } \\
\text { Kepada Tauke }\end{array}$ & Frekuensi (Orang) & Persentase (\%) \\
\hline Ya & 19 & 44,2 \\
Tidak & 24 & 55,8 \\
\hline Jumlah & 43 & 100 \\
\hline
\end{tabular}

Sumber: Hasil Olahan Data Primer (2019)

Berdasarkan Tabel 6 menunjukkan bahwa bahwa dari 43 responden, terdapat 19 atau $44,2 \%$ petani kelapa sawit memanfaatkan tauke untuk meminjam uang saat mereka kekurangan/butuh uang untuk suatu dan 24 orang atau 55,8\% lainnya memilih tidak dengan berbagai alasan.

Meminjam /Mengutang Keperluan Sehari-hari Di Warung/Toko

Tabel 7. Distribusi Frekuensi Responden Meminjam/Menghutang Keperluan Sehari-hari di Warung/Toko Di Kecamatan Sungai Bahar Kabupaten Muaro Jambi 2019.

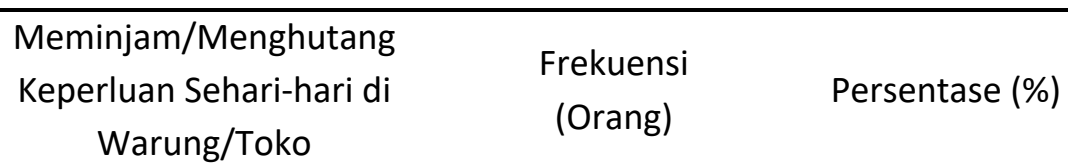




\begin{tabular}{ccc} 
Ya & 18 & 41,9 \\
Tidak & 25 & 58,1 \\
\hline Jumlah & 43 & 100 \\
\hline
\end{tabular}

Sumber: Hasil Olahan Data Primer (2019)

Berdasarkan Tabel 7 menunjukkan bahwa dari 43 responden, terdapat 18 atau 41,9\% petani kelapa sawit memanfaatkan warung/toko terdekat ataupun yang mereka kenal/sering belanja disana untuk meminjam/menghutang terlebih dahulu untuk sembako/keperluan sehari-hari lainnya dan 25 orang atau $58,1 \%$ lainnya memilih tidak.

\section{KESIMPULAN}

Strategi adaptasi yang digunakan para petani kelapa sawit di Sungai Bahar ketika menghadapi rendahnya harga jual buah kelapa sawit yaitu: (1) strategi aktif, dengan menjadi buruh tani sebesar $55,8 \%$ dan membuka usaha sampingan hanya sebesar $11,6 \%$. (2) strategi pasif, memanfaatkan pekarangan rumahnya untuk di tanami tanaman hortikultura $81,4 \%$ dan memelihara/ternak ayam sebesar 20,9\%. (3) strategi jaringan, Para petani kelapa sawit di Sungai Bahar memanfaatkan jaringan sosial mereka dengan meminjam uang kepada kekerabat/tetangga sebesar $72,1 \%$, meminjam ke tauke sebesar $44,2 \%$ serta menghutang keperluan sehari-hari di warung/toko sebesar $41,9 \%$.

Sebaiknya dilakukan pemberdayaan dan pengembangan daya kreativitas kepada para petani kelapa sawit yang hanya menggantungkan hidupnya dari hasil kebun sawitnya agar mereka mempunyai kekerativan dalam menemukan peluang usaha ataupun pekerjaan apa yang bisa dilakukan, sehingga dapat mencari usaha sampingan lainnya agar perekonomian dan pendapatannya tetap dapat stabil dan tidak terlalu khawatir ketika harga jual buah kelapa sawit turun/rendah.

\section{DAFTAR PUSTAKA}

Dinas Perkebunan Provinsi Jambi. 2017. Statistik Tanaman Perkebunan Provinsi Jambi. Provinsi Jambi.

Hutapea, Wolter Widyatama. 2016. Modal Sosial Sebagai Strategi Bertahan Hidup Buruh Tani Di Desa Kopiwangker, Kecamatan Langowan Barat, Minahasa. Jurnal AgriSosioEkonomi Unsrat

Irawan, Candra. 2018. Strategi Bertahan Hidup Petani Cabai Desa Tegalagung Kecamatan Semanding Kabupaten Tuban. Jurnal IImu Sosial dan Hukum, Universitas Negeri Surabaya. Jawa Timur

Kumesan, Finna. 2015. Strategi Bertahan Hidup (Life Survival Strategy) Buruh Tani Di Desa Tombatu Dua Utara Kecamatan Tombatu Utara. Jurnal Ekonomi. Universitas Sam Ratulangi. Sulawesi Utara

Lestari, Citra Yudha. 2015. Strategi Bertahan Hidup Petani Karet Menghadapi Harga Karet Yang Tidak Tetap (Studi Kasus Jorong Mekar Sari, Nagari Ampalu, Kecamatan Koto Salak, Kabupaten Dharmasraya. Jurnal Pendidikan Ilmu Pengetahuan Sosial. Stkip Pgri Sumatera Barat. Padang 
Siregar, Edi Iwan. 2009. Strategi Adaptasi Petani Rakyat Dalam Mensiasati Fluktuasi Harga Kelapa Sawit (Studi Kasus: Petani Kelapa Sawit Rakyat Di Desa Tanjung Medan Kec. Kampung Rakyat Kab. Labuhan Batu Selatan). Skripsi Fakultas Imu Sosial Dan Ilmu Politik. Universitas Sumatera Utara. Medan 